\title{
Physical functioning for prostate health
}

\author{
Roanne Segal, MD, FRCPC
}

Medical Oncologist, Regional Cancer Center, Medical Lead, Breast Disease Site, Head Survivorship Program, Associate Professor of Medicine, University of Ottawa, The Ottawa Hospital Regional Cancer Program, Ottawa, ON

Cite as: Can Urol Assoc J 2014;8(7-8):S162-3. http://dx.doi.org/10.5489/cuaj.2315

Published online August 11, 2014.

\section{Abstract}

Men who undergo long-term androgen deprivation therapy (ADT) may experience systemic side effects similar to the classical metabolic syndrome. Exercise is a potential strategy for offsetting the adverse effects of ADT among patients with prostate cancer, resulting in improved muscular resistance and positive outcomes on body size and composition. Fitness (aerobic capacity), fatigue and certain quality of life (QOL) outcomes may also improve in response to a regular exercise regimen. Caution and cardiovascular screening are merited given the elderly population with this disease.

\section{Introduction}

With improvements in health, sanitation and social conditions, the average life expectancy of Canadians is increasing. The result is that by 2036 , more than $20 \%$ of the population is expected to live beyond $65 .{ }^{1}$ With age comes a decline in the determinants of physical functioning, including muscle mass, strength/power and maximal exercise capacity. This in turn facilitates the accumulation of body fat and insulin resistance.

The impairments associated with aging can affect activities of daily living. Frailty may occur when impairments in function and reductions in physiologic reserves are severe enough to cause disability. ${ }^{2}$ Frailty is defined as a clinical syndrome when 3 or more the following are present: ${ }^{3}$

- Unintentional weight loss (4.5 kg in past year)

- Exhaustion (self-reported)

- Weakness (grip strength, lowest 20\%)

- Walking speed (15 feet, slowest 20\%)

- Low physical activity (kcal/week, lowest 20\%)

The endocrine changes that occur with aging include a decline in growth hormone $(\mathrm{GH})$ beginning around the third decade of life. Circulating insulin-like growth factor 1 levels decline in parallel to $\mathrm{GH}$, along with testosterone levels, leading to hypogonadism. An estimated $20 \%$ of men aged 60 to 70 are considered hypogonadal, defined by testosterone levels below $11.2 \mathrm{nmol} / \mathrm{L}{ }^{4}$ This percentage increases to $50 \%$ in men 80 and older. As a result, both exercise capacity and the anabolic hormone profile necessary for the maintenance of muscle tissue integrity are compromised in older men. Muscle function and exercise capacity can be improved through high-intensity resistance training; ${ }^{5}$ however, the hypertrophic response of muscle to training is blunted in older men compared with their younger counterparts, due in part to the deficient anabolic hormone profile. ${ }^{6,7}$ Muscle function may be further compromised in men with prostate cancer.

The development and progression of prostate cancer are dependent on signaling through the androgen receptor, and therapies that block testicular sources of androgen - or androgen deprivation therapy (ADT) - remain the cornerstone of treatment for advanced prostate cancer. Men who undergo long-term ADT may experience systemic side effects typical of the features of metabolic syndrome, including loss of muscle mass, increased fat mass and development of central adiposity, hyperlipidemia, increased risk of cardiovascular morbidity/mortality, hyperglycemia and hyperinsulinemia. ${ }^{8-11}$ Whether these changes in cardiometabolic risk factors translate to an increased risk of cardiovascular events is unclear. While some individual studies have suggested that ADT may increase a man's risk of dying from cardiovascular causes, ${ }^{12-14}$ a meta-analysis of more than 4000 patients found no evidence that ADT increases the risk of cardiovascular death among men with unfavourable-risk, non-metastatic prostate cancer. ${ }^{15}$ Nonetheless, a joint advisory by the American Heart Association, American Cancer Society and American Urological Association recommends that patients undergoing ADT be monitored for metabolic changes and provided with the appropriate secondary prevention measures. ${ }^{16}$

Exercise may be a potential strategy for offsetting the adverse effects of ADT. Resistance exercise has been shown to lessen the metabolic effects of ADT in men with prostate cancer, reducing fatigue and improving quality of life and muscular fitness. ${ }^{17}$ Among men with prostate cancer, radiotherapy may also 
result in fatigue, reduced quality of life and declines in physical fitness. Both resistance and aerobic exercise have been shown to reduce the fatigue associated with radiotherapy in men with prostate cancer. ${ }^{18}$ In the long term, resistance exercise generated longer-term improvements and additional benefits on quality of life, strength, triglycerides and body fat. Exercise may also help to attenuate the bone loss associated with ADT, thereby reducing the risk of fracture. Bone-loading activities stimulate positive changes in bone metabolism, and there is evidence that resistance training and high-impact loading exercises can positively influence bone health. ${ }^{19}$ In a systematic review, men with prostate cancer undergoing ADT benefited from exercise training, demonstrating consistent positive results in physical and muscular performance and lean body mass/muscle volume. However, effects on bone health, cardiometabolic risk markers and quality of life remain less clear. ${ }^{20}$

A consensus by the American College of Sports Medicine $(\mathrm{ACSM})^{21}$ on exercise and cancer determined that exercise is a safe and effective means of reducing many of the side effects associated with prostate cancer treatment and androgen suppression. In general, the ACSM recommends moderate-intensity aerobic physical activity for a minimum of 30 minutes, 5 days per week, or vigorous-intensity aerobic activity for a minimum of 20 minutes, 3 days per week, to promote and maintain health in older adults. ${ }^{22}$ Resistance training should be performed a minimum of 2 days a week, incorporating 8 to 10 exercises with 10 to 15 repetitions using major muscle groups during each session. Aerobic or resistance training days should also incorporate flexibility activities for a minimum of 10 minutes, involving 3 to 4 sets of 10 - to 30 -second static stretches. ${ }^{22}$

\section{Conclusions}

Exercise is a safe and effective adjunct to therapy for patients with prostate cancer. Although caution is merited given the elderly population, exercise has been shown to improve muscular resistance and result in positive outcomes on body size and composition. Fitness (aerobic capacity), fatigue, and certain quality of life outcomes may also improve in response to a regular exercise regimen.

Because energy balance appears to be an important factor in prevention and cancer-specific outcomes, moderate-intensity exercise programs are considered a safe and beneficial adjunct to the treatment plan for the aging male with or without prostate cancer. For patients with prostate cancer undergoing ADT, an exercise regimen should be considered to decrease the effects of any musculoskeletal adverse events, especially since exercise also has the potential to improve cardiovascular and overall health.

Competing interests: Dr. Segal declares no competing financial or personal interests.

\section{References}

1. Statistics Canada. Population Projections for Canada, Provinces and Territories. Catalogue no. 91-520-X. http:// www.statcan.gc.ca/tables-tableaux/sum-som/101/cst01/demo08d-eng.htm. Accessed July 7, 2014.

2. Ory MG, Schechtman KB, Miller JP, et al. Frailty and injuries in later life: The FICSIT trials. J Am Geriatr Soc 1993:41:283-96.

3. Fried L, Tangen CM, Walston J, et al. Frailty in older adults: Evidence for a phenotype. J Gerontol A Biol Sci Med Sci 2001;56:M134-5. http://dx.doi.org/10.1093/gerona/56.3.M146

4. Harman SM, Metter EJ, Tobin JD, et al. Longitudinal effects of aging on serum total and free testosterone levels in healthy men. Baltimore Longitudinal Study of Aging. J Clin Endocrinol Metab 2001;86:724-31. http:// dx.doi.org/10.1210/icem.86.2.7219

5. Fiatarone $M A, O^{\prime} N$ eill $E F$, Ryan ND, et al. Exercise training and nutritional supplementation for physical frailty in very elderly people. N Engl J Med 1994:330:1769-75. http://dx.doi.org/10.1056/NEJM199406233302501

6. Conboy IM, Conboy MJ, Wagers AJ, et al. Rejuvenation of aged progenitor cells by exposure to a young systemic environment. Nature 2005;433:760-4. http://dx.doi.org/10.1038/nature03260

7. Petrella JK, Kim JS, Cross JM, et al. Efficacy of myonuclear addition may explain differential myofiber growth among resistance-trained young and older men and women. Am J Physiol Endocrinol Metab 2006;291:E937-46. http://dx.doi.org/10.1152/aipendo.00190.2006

8. Galvão DA, Spry NA, Tauffe DR, et al. Changes in muscle, fat and bone mass after 36 weeks of maximal androgen blockade for prostate cancer. BJU Int 2008;102:44-7. http://dx.doi.org/10.1111/j.1464410X.2008.07539.x

9. Faris JE, Smith MR. Metabolic sequelae associated with androgen deprivation therapy for prostate cancer. Curr Opin Endocrinol Diabetes Obesity 2010;17:240-6. http://dx.doi.org/10.1097/MED.0b013e328339lfdl

10. Smith MR, Lee L, Nathan DM. Insulin sensitivity during combined androgen blockade for prostate cancer. J Clin Endocrinol Metabol 2006;91:1305-8. http://dx.doi.org/10.1210/ic.2005-2507

11. Basaria $S$, Muller $D C$, Carducci $M A$, et al. Hyperglycemia and insulin resistance in men with prostate carcinomo who receive androgen-deprivation therapy. Cancer 2006;106:581-8. http://dx.doi.org/10.1002/cncr.21642

12. Keating NL, $0^{\prime}$ Malley AJ, Smith MR. Diabetes and cardiovascular disease during androgen deprivation therapy for prostate cancer. J Clin Oncol 2006;24:4448-56. http://dx.doi.org/10.1200/JC0.2006.06.2497

13. Tsai HK, D'Amico AV, Sadetsky N, et al. Androgen deprivation therapy for localized prostate cancer and the risk of cardiovascular mortality. J Natl Cancer Inst 2007;99:1516-24. http://dx.doi.org/10.1093/inci/dim168

14. D'Amico AV, Chen MH, Renshaw AA, et al. Androgen suppression and radiation vs radiation alone for prostate cancer: A randomized trial. JAMA 2008;299:289-95.

15. Nguyen PL, Je Y, Schutz FA, et al. Association of androgen deprivation therapy with cardiovascular death in patients with prostate cancer: A meta-analysis of randomized trials. JAMA 2011;306:2359-66. http://dx.doi. org/10.1001/jama.2011.1745

16. Levine GN, D’Amico AV, Berger P, et al; American Heart Association Council on Clinical Cardiology and Council on Epidemiology and Prevention, the American Cancer Society, and the American Urological Association. Androgen-deprivation therapy in prostate cancer and cardiovascular risk: a science advisory from the American Heart Association, American Cancer Society, and American Urological Association: Endorsed by the American Society for Radiation Oncology. Circulation 2010;121:833-40. http://dx.doi.org/10.1161/ CIRCULATIONAHA.109.192695

17. Segal RJ, Reid RD, Courneya KS, et al. Resistance exercise in men receiving androgen deprivation therapy for prostate cancer. J Clin Oncol 2003;21:1653-9. htrp://dx.doi.org/10.1200/JC0.2003.09.534

18. Segal RJ, Reid RD, Courneya KS, et al. Randomized controlled trial of resistance or aerobic exercise in men receiving radiation therapy for prostate cancer. J Clin Oncol 2009;27:344-51. http://dx.doi.org/10.1200/ JC0.2007.15.4963

19. Guadalupe-Grau A, Fuentes T, Guerra B, et al. Exercise and bone mass in adults. Sports Med 2009;39:439-68 http://dx.doi.org/10.2165/00007256-200939060-00002

20. Gardner JR, Livingston PM, Fraser SF. Effects of exercise on treatment-related adverse effects for patients with prostate cancer receiving androgen-deprivation therapy: A systematic review. I Clin Oncol 2014;32:335-46. http://dx.doi.org/10.1200/JC0.2013.49.5523

21. Schmitz KH, Courneya KS, Matthews C, et al. American College of Sports Medicine roundtable on exercise guidelines for cancer survivors. Med Sci Sports Exerc 2010;42:1409-26. http://dx.doi.org/10.1249/ MSS.0b013e3181e0c112

22. Nelson ME, Rejeski WJ, Blair SN, et al. Physical activity and public health in older adults: Recommendation from the American College of Sports Medicine and the American Heart Association. Med Sci Sports Exerc 2007;39:1435-45. http://dx.doi.org/10.1249/mss.0b013e3180616aa2

Correspondence: Dr. Roanne Segal, Department of Medical Oncology, Ottawa Hospital, 503 Smyth Rd, Box 911, Ottawa, ON K1H 1C4 